\title{
HANSENÍASE, PRECONCEITO E PARRHESÍA: CONTRIBUIÇÕES PARA SE PENSAR SAÚDE, EDUCAÇÃO E EDUCAÇÃO EM SAÚDE
}

\section{Hansen's disease, prejudice and parrhesia: reflective contributions on health, education and health education}

\author{
Marcia Bastos de Sá ${ }^{1}$. Vera Helena Ferraz de Siqueira ${ }^{2}$
}

Resumo: Considerando que os campos profissionais da educação, da saúde e da educação em saúde implicam práticas destinadas ao governo das condutas dos indivíduos, desenvolvemos reflexão que visa contribuir para a problematização da formação profissional nesses campos. A partir de depoimento extraído de vídeo educativo que apresenta o tema do preconceito e do isolamento compulsório para portadores de hanseníase, tecemos considerações sobre a peculiaridade dos mecanismos de exclusão, conforme postulado por Michel Foucault, e apresentamos exemplos que evidenciam até que ponto esses mecanismos funcionaram, ainda recentemente, sobre os portadores da doença no Brasil. Retomando o fio dos eventos que levaram à mudança da denominação da doença - de lepra para hanseníase -, analisamos a luta empreendida por médico brasileiro contra o preconceito, alcançando uma reflexão de caráter ético, seguindo pistas das últimas investigações foucaultianas sobre o tema da constituição do sujeito moral e ativo, soberano de si mesmo.

Palavras-chave: Hanseníase. Preconceito. Saúde e educação. Michel Foucault. Formação profissional. Ética.

\begin{abstract}
We consider that the professional fields of education, health and health education have practices that govern the conduct of individuals so we developed a reflection that aims to contribute towards problematizing professional training in these fields. Based on a testimony extracted from an educational video that presents the theme of prejudice and compulsory isolation for people with Hansen's disease, we discuss the peculiarity of the exclusion mechanisms, as postulated by Michel Foucault, and present examples that show to what extent these mechanisms have still functioned recently with those who have the disease in Brazil. Revisiting the events that led to the change of the disease's name - from leprosy to Hansen's disease - we analyzed the struggle of a Brazilian doctor against prejudice, making an ethical reflection following the clues of the Foucaultian investigations on the theme of the constitution of the moral and active subject, the sovereign of himself.
\end{abstract}

Keywords: Hansen's disease. Prejudice. Health and education. Michel Foucault. Professional formation. Ethics.

\footnotetext{
${ }^{1}$ Programa de Formação Continuada Mídias na Educação, Universidade Federal do Rio de Janeiro (UFRJ). Rua Comandante Vergueiro da Cruz, 187, casa 12, Olaria. Rio de Janeiro, RJ, Brasil. 21.021-020. marciabsa@hotmail.com

${ }^{2}$ Núcleo de Tecnologia Educacional para a Saúde (Nutes), UFRJ. Rio de Janeiro, RJ, Brasil.
} 
Sá, M. B.; Siqueira, V. H. F.

\section{Introdução}

Neste artigo partimos do pressuposto de que pensar educação, saúde e a educação em saúde - campos em que a formação e o exercício profissionais envolvem o desenvolvimento de práticas destinadas ao governo das condutas de indivíduos - implica uma permanente retomada de reflexões acerca dos processos de subjetivação que ocorrem em nossa sociedade. Visando contribuir com os debates sobre o tema, especialmente no que se refere à possibilidade de uma autoformação ética e política pelos sujeitos, procuramos apontar para o potencial transformador dos profissionais que, de algum modo, para a realização do seu fazer, mantêm relações com outros indivíduos - relações de governo, entendendo-se que estas últimas, no sentido específico atribuído por Foucault, por serem flexíveis e maleáveis, dão abertura para práticas que favoreçam a constituição do outro, não como um sujeito subjugado, mas como um sujeito soberano de si mesmo.

Para tanto, iniciamos apresentando um depoimento extraído de vídeo educativo produzido pelo Núcleo de Tecnologia Educacional para a Saúde (NUTES) da Universidade Federal do Rio de Janeiro (UFRJ), o qual apresenta o tema do preconceito e da exclusão social em relação à doença e ao seu portador, para então tecer considerações sobre a peculiaridade do modelo de exclusão que ela engendra, conforme postulado por Foucault $(1989,2002)$. A seguir, são apresentados exemplos que evidenciam até que ponto a marcação e a repartição diferencial, mecanismos de exclusão, funcionaram, até bem pouco tempo, sobre os portadores de hanseníase no Brasil. Retomando o fio dos eventos que levaram à mudança da denominação da doença - de lepra para hanseníase -, analisamos a luta empreendida por médico brasileiro, dr. Abrahão Rotberg, contra o preconceito, e propomos uma reflexão de caráter ético, baseada em pistas das últimas investigações foucaultianas sobre o tema da constituição do sujeito moral e ativo, soberano de si mesmo, fundamentais, a nosso ver, para os debates relativos à educação, saúde e educação em saúde.

A abordagem médica da hanseníase no Brasil, tal como ela é entendida desde a década de 1950 - doença infectocontagiosa, tratável e curável, desde que diagnosticada precocemente - tendo em vista o alcance de uma meta maior - a sua erradicação -, implicou, e ainda implica, um trabalho voltado para "o esclarecimento da população e, em especial, a reorientação social, científica e tecnológica dos profissionais e serviços de saúde" (BRASIL, 1989, p. 16).

Esse trabalho de esclarecimento inclui, necessariamente, uma reflexão a respeito do medo e dos preconceitos associados à doença, ambos fundados nas "deformidades ou ulcerações visíveis" e "nos falsos conceitos sobre a transmissibilidade e possibilidade de cura", mantendo-se presente, ainda hoje, traços de "uma rejeição pela sociedade e até por profissionais de saúde" (BRASIL, 1989, p. 17).

Contribuem, ainda, para o aumento do medo do contágio, a associação da hanseníase e seus portadores, com o antigo significado religioso da 'lepra' e dos 'leprosos' (AZULAY, 2001; BROWNE, 2003; MACIEL, 2007; MONTEIRO, 2003), e com a própria prática do isolamento compulsório, medida utilizada em todos os países do mundo antes da descoberta das formas de contágio, do agente causador e do tratamento da doença. 


\section{Preconceito e solidão, faces de uma mesma moeda}

Com 18 minutos de duração, o vídeo "Prá onde é que eu vou?" (1988) apresenta o tema do preconceito em relação à doença e ao seu portador, em sequência com nove planos que apresentam trechos de depoimento feito por portador de hanseníase, e, outra, com catorze planos que mostram as respostas de entrevistados a respeito da patologia, além de encenação de médico que, partindo de lembranças, fala sobre as dificuldades e especificidades do tratamento dos pacientes por ela acometidos.

O título do vídeo dá destaque para a pergunta colocada, por portador de severas deformidades físicas provocadas pela hanseníase, ao final de depoimento apresentado em sequência montada com extratos de planos de sua fala, conforme transcrição a seguir ${ }^{3}$ :

P1 - "Nós estamos diante de uma doença que é... não é aceito o doente por causa das sequelas que são impressionantes..."

P2 - "então... mas... no meu caso não há perigo de contágio..."

P3 - "então é uma doença profundamente misteriosa e que cria uma situação muito... difíceis..."

P4 - "os médicos da época disseram que todos doentes de hanseníase deviam ser hospitalizados em hospitais fechados..."

P5 - "além da doença ainda tem a feiúra que impressiona. Nós somos muito infelizes porque não temos opções..."

P6 - "o senhor pode cortar minha mão aqui de machado eu não sinto nada... Sou um homem morto..."

P7 - "olha ... sou seco, todo feio... meu neto de quatro anos diz assim: avô o senhor é tão feio. Por que meu neto? Porque cê é torto... Criança não mente..."

P8 - "Por exemplo, minha família, não me aceita. O meu irmão, nunca fui na casa dele, ele nunca veio aqui. As minhas irmãs vêm do Ceará aqui, nunca me visitaram. E disse no telefone: eu não vou aí nem você vem aqui, que nós não queremos te ver...”

P9 - "Eu, por exemplo, pagaria... um irmão meu... que é... chegou ao último cargo do Banco do Brasil, é rico... disse que eu procure um asilo que ele paga. Mas eu andei procurando e não encontro esse asilo porque ninguém me aceita. Pra onde é que vou?"

O depoimento editado, ou seja, o texto produzido pela colagem de extratos do depoimento originalmente gravado, procura conduzir a atenção do espectador para aspectos pessoais e sociais decorrentes da prática da internação compulsória para os portadores da hanse-

\footnotetext{
${ }^{3}$ A letra P seguida por número refere-se ao número do plano na sequência do depoimento editado. Reticências no final das frases representam o corte do plano e, consequentemente, o corte na fala do depoente. Reticências no interior dos textos se referem a paradas, titubeios e retomadas de fala pelo depoente.
} 
níase - medida implantada pelo Governo Federal a partir de 1924, com base no pressuposto de que, retirando o doente das ruas ou estradas, os sadios estariam a salvo. $\mathrm{O}$ isolamento compulsório foi desaconselhado desde o final dos anos 1940, não recomendado em 1958, oficialmente revogado em 1962, mas só abolido, de fato, em 1986, após recomendação da VIII Conferência Nacional de Saúde (MACHADO, 2008).

Foucault $(1989,2002)$ aborda o tema da 'lepra' concentrando-se sobre a peculiaridade do modelo de exclusão que ela engendra, sobretudo quando comparado ao modelo disciplinar da peste: expurgo do impuro no primeiro e inclusão do pestilento no segundo.

A exclusão dos leprosos como prática social, segundo Foucault (2002, p. 54) estabelecia "uma divisão rigorosa, um distanciamento, uma regra de não-contato entre um indivíduo (ou um grupo de indivíduos) e outro", colocando e mantendo, fora dos limites da comunidade, os indivíduos rejeitados, que, a partir de então, se tornavam desqualificados jurídica e politicamente. A exclusão da lepra

[...] era, de um lado, a rejeição desses indivíduos num mundo exterior, confuso, fora dos muros da cidade, fora dos limites da comunidade. Constituição, por conseguinte, de duas massas estranhas uma à outra. E a que era rejeitada, era rejeitada no sentido estrito das trevas exteriores. Enfim, em terceiro lugar, essa exclusão do leproso implicava a desqualificação - talvez não exatamente moral, mas em todo caso jurídica e política - dos indivíduos assim excluídos e expulsos. [...]. Em suma, eram de fato práticas de exclusão, práticas de rejeição, práticas de 'marginalização’, como diríamos hoje. Ora, é sob essa forma que se descreve, e a meu ver ainda hoje, a maneira como o poder se exerce sobre os loucos, sobre os doentes, sobre os criminosos, sobre os desviantes, sobre as crianças, sobre os pobres. Descrevem-se em geral os efeitos e os mecanismos de poder que se exercem sobre eles como mecanismos e efeitos de exclusão, de desqualificação, de exílio, de rejeição, de privação, de recusa, de desconhecimento; ou seja, todo o arsenal dos conceitos e mecanismos da exclusão. (FOUCAULT, 2002, p. 54)

Ainda segundo o autor, "o modelo de exclusão dos leprosos, o modelo do indivíduo expulso para purificar a comunidade, acabou desaparecendo, grosso modo, em fins do século XVII - início do século XVIII" (FOUCAULT, 2002, p. 55, grifo do autor). Interessante notar que o período de desaparecimento da lepra na Europa parece corresponder ao do seu surgimento no Brasil, já que os primeiros casos foram notificados no ano de 1600, na cidade do Rio de Janeiro. A primeira ação de internamento de leprosos em território brasileiro data de 1741, quando, por ordem do governador-geral do Rio de Janeiro, Gomes Freire de Andrade (Conde de Bobadella), recolheram-se e foram sustentados por suas esmolas, cinquenta e dois leprosos em pequenas casas em São Cristóvão, sob os cuidados oferecidos por enfermeiros voluntários, frades franciscanos e negras condenadas por crimes graves (PORTO; OLIVEIRA, 1996).

Um segundo modelo, quase tão antigo quanto o da exclusão dos leprosos, foi elaborado em função do problema da peste e da cidade empesteada, a partir da prática da quarentena, que, embora similarmente ao modelo da lepra, circunscrevesse e encerrasse, em um terri- 
tório determinado nas cidades, pessoas que representavam risco à saúde do resto da população, diferenciava-se pelo desenvolvimento de uma série de práticas de controle minuciosas, que visavam

[...] as divisões estritas; [...] a penetração do regulamento até nos mais finos detalhes da existência e por meio de uma hierarquia completa que realiza o funcionamento capilar do poder; [...] a determinação a cada um de seu 'verdadeiro' nome, de seu 'verdadeiro' lugar, de seu 'verdadeiro' corpo e da 'verdadeira' doença. A peste como forma real e, ao mesmo tempo, imaginária da doença tem a disciplina como correlato médico e político. Atrás dos dispositivos disciplinares se lê o terror dos 'contágios', da peste, das revoltas, dos crimes, da vagabundagem, das deserções, das pessoas que aparecem e desaparecem, vivem e morrem na desordem. (FOUCAULT, 1989, p. 175)

O surgimento do modelo da peste corresponde a um processo histórico de invenção das tecnologias positivas de poder, pois se a 'lepra' suscitava uma reação negativa, de rejeição, de exclusão, a peste provoca uma reação positiva, "de inclusão, de observação, de formação de saber, de multiplicação dos efeitos de poder a partir do acúmulo da observação e do saber" (FOUCAULT, 2002, p. 59). Com isso,

[...] passou-se de uma tecnologia do poder que expulsa, que exclui, que bane, que marginaliza, que reprime, a um poder que é enfim um poder positivo, um poder que fabrica, um poder que observa, um poder que sabe e um poder que se multiplica a partir de seus próprios efeitos. (FOUCAULT, 2002, p. 60)

Assim, a imagem da lepra que está no fundo do modelo de exclusão afirma a importância do contato a ser cortado; enquanto a da peste, valendo por todas as desordens e confusões, está na base dos esquemas disciplinares. Embora diferentes, as práticas de exclusão e as disciplinares não são incompatíveis e se aproximam no século XIX, quando é

[...] aplicado ao espaço de exclusão de que o leproso era o habitante simbólico (e os mendigos, os vagabundos, os loucos, os violentos formavam a população real) a técnica de poder própria do 'quadriculamento' disciplinar. Tratar os 'leprosos' como 'pestilentos', projetar recortes finos da disciplina sobre o espaço confuso do internamento, trabalhá-lo com os métodos de repartição analítica do poder, individualizar os excluídos, mas utilizar processos de individualização para marcar exclusões - isso é o que foi regularmente realizado pelo poder disciplinar desde o começo do século XIX: o asilo psiquiátrico, a penitenciária, a casa de correção, o estabelecimento de educação vigiada, e por um lado os hospitais, de um modo geral todas as instâncias de controle individual funcional num duplo modo: o da divisão binária e 
Sá, M. B.; Siqueira, V. H. F.

da marcação (louco-não louco; perigoso-inofensivo; normal-anormal); e o da determinação coercitiva, da repartição diferencial (quem é ele; onde deve estar; como caracterizá-lo, como reconhecê-lo, como exercer sobre ele, de maneira individual, uma vigilância constante, etc.). (FOUCAULT, 1989, p. 176)

Assim, ao mesmo tempo, impõem-se aos excluídos - na situação específica sobre a qual nos detemos, aos 'leprosos' - as "disciplinas individualizantes" e a "universalidade dos controles disciplinares", permitindo a marcação de quem é 'leproso', e fazendo funcionar "contra ele os mecanismos dualistas da exclusão" - a divisão binária e a marcação, por um lado, e, por outro, a determinação coercitiva e a repartição diferencial (FOUCAULT, 1989, p. 176).

Para concluir essas considerações sobre os mecanismos de controle que foram aplicados à 'lepra' e aos 'leprosos' - tomados por Foucault $(1989,2002)$ como figuras simbólicas de tudo que representava, até o início do século XIX, desordem e ameaça, posto que, de fato, tal doença, por confluência de diversos fatores acabou mesmo desaparecendo da Europa - apresentamos dois exemplos, com os quais nos deparamos durante as investigações, de até que ponto a marcação e a repartição diferencial, mecanismos de exclusão, funcionaram no Brasil, até bem pouco tempo, sobre os portadores de hanseníase no Brasil.

O primeiro achado, veiculado no Boletim Informativo (2006) da Associação Filatélica e Numismática de Santa Catarina, se refere ao pedido de fabricação de moedas para a Colônia Santa Tereza, situada em Florianópolis e inaugurada em março de 1940, visando à manutenção do pequeno comércio no interior da Colônia, pois

[...] nada saía sem controle oficial. Ora, para existir comércio era necessário numerário, e como não podia haver a circulação do dinheiro nacionalmente vigente, foi idealizada a fabricação de um outro dinheiro, somente para uso local. Essa idéia permitiria o não manuseio do dinheiro vigente, evitando-se, assim, que a doença se espalhasse mais facilmente. [...]. A reforma monetária brasileira de 05 de outubro de 1942 não afetou o comércio interno, que continuou a usar as moedas com o padrão Mil Réis. (BOLETIM INFORMATIVO, 2006, p. 11)

O segundo achado se refere ao recente movimento dos filhos separados, também compulsoriamente, de seus pais com hanseníase, entre as décadas de 1930 e 1970. Em 20 de março de 2011, foi realizado, na cidade de Itu, São Paulo, o $1^{\circ}$ Encontrão dos Filhos que foram Separados pelo Isolamento Compulsório do Estado de São Paulo, contando com o apoio do Movimento de Reintegração das Pessoas Atingidas pela Hanseníase (MORHAN) de Barueri, São Paulo. De acordo com o dossiê 'A história dos filhos órfãos de pais vivos no Brasil' (ARAÚJO, 2010), são mais de 30 mil filhos espalhados por todo o Brasil, e o objetivo do movimento é alcançar o reconhecimento e resposta do Governo Federal sobre indenização pleiteada para os filhos que foram separados dos seus pais.

No Brasil, a extinção da prática do isolamento compulsório, e, até mesmo a substituição do termo 'lepra' e seus derivados, por uma terminologia oficial designada a partir do termo 'hansen', referência ao pesquisador que descobriu o bacilo causador da doença, não 
foram suficientes para produzir efeitos diretos, imediatos, sobre os preconceitos e os temores vinculados à doença, entendidos como um dos fatores responsáveis pela permanência do Brasil na lista dos países com alta endemicidade da hanseníase.

\section{Lepra e hanseníase: sinônimos?}

No vídeo analisado (PRÁ ONDE..., 1988), as respostas dos entrevistados à pergunta 'você sabe o que é hanseníase?' identificam a doença como sinônimo de 'lepra'. Mas, seriam, de fato, lepra e hanseníase a mesma doença?

Em linhas gerais, tendemos à compreensão - tomando, ainda, o referencial foucaultiano como base e, especialmente, suas contribuições sobre a configuração geral dos saberes e a construção do objeto em diferentes períodos da história - de que 'lepra' e hanseníase não são a mesma doença, porque pertencem a epistemes distintas. Além disso, entendemos que as investigações sobre os aspectos culturais/sociais negativos ligados à hanseníase, no caso específico do Brasil, poderiam ser aprofundadas a partir da consideração da concomitância das medidas excludentes características do controle da hanseníase - que recrudesceram, especialmente em São Paulo, a partir dos anos 1940 -, com práticas e discursos oriundos de fenômenos político-sociais ocorridos a partir dos anos 1930, a saber: ascensão e domínio do nazismo, do fascismo e do stalinismo. Para tal intento, o curso 'Em defesa da sociedade', do Collège de France, de 1975-1976 (FOUCAULT, 2005), poderá indicar pistas interessantes.

A substituição da denominação lepra por hanseníase foi oficializada no Brasil, pela Lei n ${ }^{\circ}$ 9.010, de 29 de março de 1995 (BRASIL, 1995), que dispôs "sobre a terminologia oficial relativa à hanseníase” (BRASIL, 1995, p. 1), conforme transcrição abaixo:

Art. $1^{\circ} \mathrm{O}$ termo 'lepra' e seus derivados não poderão ser utilizados na linguagem empregada nos documentos oficiais da Administração centralizada e descentralizada da União e dos Estados-membros.

Art. $2^{\circ} \mathrm{Na}$ designação da doença e de seus derivados far-se-á uso da terminologia oficial constante da relação abaixo

\begin{tabular}{ll} 
Terminologia Oficial & Terminologia Substituída \\
Hanseníase & Lepra \\
Doente de Hanseníase & Leproso, Doente de Lepra \\
Hansenologia & Leprologia \\
Hansenologista & Leprologista \\
Hansênico & Leprótico \\
Hansenóide & Lepróide \\
Hansênide & Lépride \\
Hansenoma & Leproma \\
Hanseníase Virchoviana & Lepra Lepromotosa \\
Hanseníase Tuberculóide & Lepra Tuberculóide \\
Hanseníase Dimorfa & Lepra Dimorfa \\
\multicolumn{2}{l}{ Hanseníase Indeterminada } \\
Lepra Indeterminada \\
Antígeno de Mitsuda & Lepromina
\end{tabular}


Sá, M. B.; Siqueira, V. H. F.

Hospital de Dermatologia Leprosário, Leprocômio

Sanitária, de Patologia

Tropical ou Similares

Art. $3^{\circ}$ Não terão curso nas repartições dos Governos, da União e dos

Estados, quaisquer papéis que não observem a terminologia oficial ora estabelecida, os quais serão imediatamente arquivados, notificando-se a parte. (BRASIL, 1995, p. 1)

Vinte anos antes, em 05 de agosto de 1975, é publicado, no Diário Oficial da União, o Decreto 76.078, de 04/08/1975 (BRASIL, 1975), que altera "a denominação de Órgãos do Ministério da Saúde" (BRASIL, 1975, p. 1).

Art. $1^{\circ}$ A Divisão Nacional de Lepra e a Campanha Nacional Contra a Lepra, integrantes da Secretaria Nacional de Saúde, a que se refere o número 1 , letra 'e', do artigo $2^{\circ}$ do Decreto número 74.891, de 13 de novembro de 1974, que dispõe sobre a estrutura básica do Ministério da Saúde, passam a denominar-se, respectivamente Divisão Nacional de Dermatologia Sanitária e Campanha Nacional Contra a Hanseníase.

Art. $2^{\circ}$ A Divisão Nacional de Dermatologia Sanitária tem por finalidade planejar, orientar, coordenar, auxiliar, controlar, fiscalizar e executar, supletivamente, atividades de prevenção da hanseníase e de outras dermatoses de interesse sanitário, bem como o tratamento específico e a reabilitação dos seus portadores. (BRASIL, 1975, p. 1)

Apesar de as legislações sobre a mudança terminológica terem sido publicadas em 1995 e 1975 (BRASIL, 1975, 1995), a proposta de tal medida começara a circular nos meios acadêmicos e em órgãos voltados ao combate da lepra desde a década de 1960, especialmente após a revogação da prática do isolamento compulsório, pela aprovação do Decreto 968, de 07 de maio de 1962 (BRASIL, 1962).

Kliemann (2006) e Opromolla e Martelli (2005) concordam que o proponente dessa mudança foi o médico Abrahão Rotberg. Entretanto, dão destaque para situações diversas: o primeiro faz alusão ao ano de 1967, quando o dr. Rotberg assumiu a direção do Departamento de Profilaxia da Lepra de São Paulo. Opromolla e Martelli (2005), por seu turno, se referem à apresentação da proposta a Walter Lezer, então Secretário de Saúde do Estado de São Paulo, que, junto com um comitê técnico do mesmo órgão, publica uma resolução determinando a criação de novo vocabulário para classificar a doença em dezembro de 1970.

A mudança da palavra 'lepra' para hanseníase não resultou, como se poderia pensar, de artimanhas governamentais que pretendiam fazer desaparecer a lepra do país. Na verdade, as várias pesquisas e projetos dedicados à investigação da história da hanseníase no Brasil apontam para o oposto: com a revogação do isolamento compulsório em 1962, mesmo que não acatada imediatamente em todos os Estados, desocultaram-se não apenas os 'leprosos', mas, sobretudo, uma série de problemas vinculados ao preconceito e ao desconhecimento em relação à doença, que, unificados sob a bandeira de luta da mudança terminológica, entraram e permaneceram, de certo modo até hoje, em várias agendas de debates brasileiras e internacionais. 
Todos os dados levantados até o momento indicam que, de fato, o lançamento da proposta de mudança terminológica coube ao dr. Abrahão Rotberg, e, mesmo que não tenha cabido exclusivamente a ele, é preciso reconhecer seu empenho à causa, empenho este acessível à análise, a partir dos editoriais e artigos por ele assinados e publicados na revista Hansenologia Internationalis (ROTBERG, 1976, 1977, 1978a, 1978b, 1978c, 1979a, 1979b, 1979c, 1980, 1981, 1983), quando o termo 'lepra' é permanentemente atacado em favor do uso de termos derivados do sobrenome do pesquisador que descobriu o bacilo causador da doença em 1873, o médico norueguês Gerhadt Henrik Armauer Hansen. A leitura dos textos de Rotberg indicados acima torna-se ainda mais interessante se consideramos as informações elencadas a seguir.

A revista "Hansenologia Internationalis", lançada pelo dr. Rotberg em 1974, foi, na verdade, um relançamento, sob um novo título e com novo direcionamento do perfil editorial, da "Revista de Leprologia de São Paulo", lançada em 1934, também com a participação do médico; em 1936, devido ao acordo firmado entre o Centro Internacional de Leprologia, no Rio de Janeiro, e a Sociedade Paulista de Leprologia, a publicação passou a se chamar "Revista Brasileira de Leprologia", assim permanecendo até a suspensão de suas atividades em 1971. Segundo Maciel (2007, p. 81), essa revista

[...] representou um espaço de diálogo importante que, para além de ratificar uma prática terapêutica implantada pelo Estado e assentada no isolamento, era objeto de consolidação de uma especialização profissional, divulgando um saber que formava novas gerações. Segundo Yara Monteiro [2003], a formação e atuação desses profissionais especializados representavam a manutenção da rede de poder, de interferência e de alcance, criada pelo Departamento de Profilaxia da Lepra do Estado de São Paulo. Nesse sentido, os leprologistas partilhavam de um discurso técnico bastante hermético que se sustentava numa legitimidade cultural restrita aos iniciados, pois que se mantinham 'encastelados' em suas trincheiras, sem uma comunicação rotineira com o discurso e a prática dos 'de fora'.

Os leprologistas paulistas, sob a influência do diretor do "Departamento de Profilaxia da Lepra" do seu Estado, o dr. Salles Gomes - personalidade carismática, centralizadora e totalmente a favor das práticas isolacionistas -, desenvolveram uma prática individualizada e autônoma, distanciada de qualquer outra realidade que não a do Departamento (MACIEL, 2007). Segundo o dr. Rotberg, em depoimento ao Projeto 'Memória e história da hanseníase no Brasil através de seus depoentes - 1960/2000', Casa de Oswaldo Cruz (COC) da Fundação Instituto Oswaldo Cruz (FIOCRUZ) em parceria com a Universidade Federal do Rio de Janeiro (UFRJ):

[...] a política do Departamento era o isolamento compulsório, e se isolava a torto e a direito, gente que precisava, gente que não precisava. Eu vi barbaridades. Uma das barbaridades que eu vi foi a internação de uma criança que tinha hanseníase tuberculóide. Um menino de nove anos, nunca me esqueço do caso. Ele deixando a família, a famí- 
Sá, M. B.; Siqueira, V. H. F.

lia deixando o menino. (choro) [Os inspetores sanitários] eram sujeitos [que] entravam nas casas, tiravam crianças com hanseníase tuberculóide, internavam nos hospitais [...] Mas já havia gente que suspeitava que aquilo era uma estupidez, era burrice, coisa e tal, mas ninguém convencia o Salles Gomes, sabe? Era isolamento total. Ele era muito duro e aqueles assistentes de saúde, assistentes sanitários, eram verdadeiras feras. Eles queriam diagnosticar, para internar [...] não havia critério nenhum... [O Salles Gomes] tinha muita força política. [Sua] viúva era ligada aos Guinle do Rio... e os Guinle eram unha e carne com a ditadura. Um ou outro advogado queria defender baseado nisso [...] na estupidez que foi o isolamento. E nós? O que fazíamos? Nós éramos funcionários públicos, dependíamos daqueles salários... E algum de nós que reclamasse era posto no olho da rua. (ROTBERG, 2002 apud MACIEL, 2007, p. 83)

E ainda mais, acrescenta Maciel (2007, p. 83):

[...] Rotberg afirma que com sua formação em medicina e especialização em leprologia estava proibido, por lei estadual, de fazer o atendimento a quaisquer pacientes com casos suspeitos de lepra em seu consultório particular. Estes deveriam ser atendidos somente na rede pública, ou seja, exclusivamente pelos médicos e guardas sanitários do Departamento de Profilaxia da Lepra que encaminhavam para o isolamento de maneira compulsória.

Uma oposição às ideias isolacionistas do Departamento paulista - permanentemente retomadas e reforçadas positivamente visando uma justificação inquestionável para o isolamento como prática profilática - exigia coragem, pois tal discordância elevava o opositor, sempre alguém tornado especialista sob os auspícios do Estado, à condição de "inimigo da causa profilática paulista” (MACIEL, 2007, p. 84) e, portanto, passível de punição, como a transferência-exílio para o Asilo de Cocais, a demissão, ou até mesmo, a total impossibilidade de continuar a praticar a especialidade em São Paulo, obrigando o profissional à mudança de Estado (MACIEL, 2007).

Para o dr. Rotberg, o posicionamento contrário à política empreendida pelo Departamento sob a administração de Salles Gomes só pôde ocorrer após sua aposentadoria em 1959, quando sentiu-se "suficientemente crítico" em relação ao isolamento compulsório e "ciente do fracasso da sua tão propagada eficácia" (MACIEL, 2007, p. 84).

A partir de 1960, o dr. Rotberg inicia sua carreira no magistério, lecionando dermatologia na Escola Paulista de Medicina, e assume, em 1967, a convite de Walter Lezer, a direção do Departamento de Profilaxia da Lepra, tendo por missão maior, fazer cumprir, no Estado de São Paulo, a recomendação do decreto de 1962, de extinção da prática do isolamento, que só logrou êxito, paulatinamente, após as negociações empreendidas pelo médico. 


\section{Constituindo-se como sujeito moral e ativo: a luta contra o preconceito}

Gostaríamos de dar destaque à figura do dr. Rotberg, esse personagem que encarna a luta contra o preconceito em relação à hanseníase. Tecemos, a seguir, considerações que avaliamos interessantes a respeito do homem que escreveu todos os títulos elencados anteriormente, um Rotberg corroído por um silêncio que, finalmente, não precisava mais suportar, mas, talvez, ainda atormentado por tudo que viu, ouviu e permitiu demais. "Eu vi barbaridades" (ROTBERG, 2002 apud MACIEL, 2007, p. 83), disse ele. E talvez para expurgar de si e do mundo todas as cenas, práticas e discursos que fazem parte das suas lembranças, na tentativa de impedir que tudo aconteça novamente, escreve. Uma escrita onde talvez procure se reescrever; com certeza, uma escrita carregada do desejo de mudança - mudar palavras, mudar práticas, mudar a sua história, mudar a si mesmo, mudar a história.

Os textos de Rotberg nos reenviaram a algumas noções trabalhadas por Foucault (2006) no curso 'A hermenêutica do sujeito', investigação que estabelece como tema central “o cuidado de si, desde Platão até os filósofos epicuristas e estoicos dos dois primeiros séculos da era cristã, em contraposição ao conbecimento de si, tema clássico da tradição filosófica" (GROS, 2004, p. 08, grifo... grifos do autor). São elas: os hypomnêmata e a parrhesía.

Segundo Foucault (2006, p. 433), os denominados bypomnêmata, pelos gregos antigos, são "suporte de lembranças", ou seja, anotações feitas sobre leituras, conversas, aulas, pensamentos ocorridos, a fim de guardá-las à disposição para rememorar as coisas ditas, conversadas, pensadas. A escrita, nesse sentido, se coloca como "um elemento de exercício", podendo ser usada de dois modos simultâneos: primeiro, um "uso para nós mesmos", pois

[...] é escrevendo, precisamente, que assimilamos a própria coisa na qual se pensa. Nós a ajudamos a implantar-se na alma, a implantar-se no corpo, a tornar-se como que uma espécie de hábito, ou em todo caso de virtualidade física. Era hábito, e hábito recomendado, escrever aquilo que se tivesse lido, e uma vez escrito, reler aquilo que se tivesse escrito, e relê-lo necessariamente em voz alta, pois como sabemos, na escrita latina e grega, as palavras não eram separadas umas das outras. Isto significa que havia uma grande dificuldade em ler. $\mathrm{O}$ exercício de leitura não era fácil: não se tratava simplesmente de ler com os olhos. Para se chegar a destacar as palavras como convinha, era-se obrigado a pronunciá-las, pronunciá-las em voz baixa. De sorte que o exercício de ler, escrever, reler o que tinha escrito e as anotações feitas, constituía um exercício quase físico de assimilação da verdade e do logos a se reter. (FOUCAULT, 2006, p. 432, grifo do autor)

Mas, essa escrita também poderia servir a outros, pois

[...] nesta troca maleável de serviços da alma em que ajudamos o outro no seu caminho para o bem e para ele próprio, compreendemos que a atividade da escrita seja importante. [...]. Vemos então - e este é também um fenômeno de cultura, um fenômeno social muito interessante 
Sá, M. B.; Siqueira, V. H. F.

nessa época - quanto a correspondência [...] espiritual, correspondência de alma, correspondência de sujeito a sujeito, correspondência cuja finalidade [...] [era] dar um ao outro notícias de si mesmo, indagar sobre o que se passava na alma do outro, ou pedir ao outro que desse notícias do que se passava com ele, portanto, o quanto tudo isto se tornou naquele momento uma atividade extremamente importante, atividade, se quisermos com uma dupla face. (FOUCAULT, 2006, p. 433)

A dupla face das correspondências, apontada por Foucault (2006) no extrato acima, se refere à permissão do exercício de aconselhamento feito por quem se encontra mais avançado na virtude e no bem, a outro, visando o progresso de quem recebe os conselhos; esse exercício possibilita, concomitantemente, "àquele que dá conselhos recordar as verdades que fornece ao outro e das quais ele próprio tem necessidade para sua vida" (FOUCAULT, 2006, p. 434). Assim, quem se corresponde com o outro, cumprindo uma função de diretor de alma, "faz continuamente exercícios, de certo modo pessoais, uma ginástica que se destina ao outro, mas também a si, e que permite, por esta correspondência, manter-se perpetuamente em estado de autodireção" (FOUCAULT, 2006, p. 434).

Os escritos de Rotberg (1976, 1977, 1978a, 1978b, 1978c, 1979a, 1979b, 1979c, 1980, 1981, 1983), em vários momentos, causam a impressão de que serviam, por um lado, como diários, como cadernos de notas, onde retomava argumentos já desenvolvidos em textos anteriores, acrescentando novos dados ou elementos retóricos, ou fazia referência a artigos enviados a outros periódicos para criar uma linha do tempo dos debates, das tentativas de aprovação da sua proposta de mudança da terminologia referida à hanseníase em nível internacional; por outro lado, o editorial da revista era utilizado como espaço de denúncia e de guerra contra práticas e discursos que se aproveitavam do sentido pejorativo ligado ao termo 'lepra', tal como observado nos títulos: 'O décimo aniversário dos 'leprosos lunares' (1979c) e 'Thanks to Time, Newsweek, Siete Dias, o Cruzeiro, and others' (1981).

Existe algo de heroico na trajetória do homem Rotberg: enquanto médico do "Departamento de Profilaxia da Lepra" do Estado de São Paulo, permaneceu submisso a todas as normas e proibições, para não arriscar perder trabalho, salário, posição, e, embora testemunhasse ações com as quais não concordava, acovardou-se; talvez tenha 'recolhido fúrias', mas foi omisso, manteve-se sob o governo de outros, para não sofrer prejuízos. Após sua aposentadoria, livre da figura 'hipnótica' do poderoso Salles Gomes, passou a dar mais crédito às suas percepções, aos seus saberes, reconhecendo-se 'suficientemente crítico' em relação às práticas e discursos dos quais participou durante tantos anos (MACIEL, 2007, p. 84). Ocorre, então, a passagem do antigo e jovem Rotberg, submisso ao governo de outrem, para o Rotberg adulto, maduro, enfim dedicado à transcendência da sua própria condição humana, autoconsagrado a uma luta na qual acreditava absolutamente - a luta contra os preconceitos em relação à hanseníase e seus portadores, segundo ele, preconceito ancorado no termo lepra, erroneamente adotado pelos médicos, tal como tratado em seu escrito "A non-stigmatizing Bible" (1978a).

Considerando o material ao qual tivemos acesso, Rotberg, de fato, mudou seu discurso e sua atitude em relação às práticas sociais e médicas dirigidas à hanseníase; provavelmente, seu deslocamento se iniciou em 1960, quando começou a exercer a função de professor, uma das possíveis faces do antigo 'diretor de consciência' da cultura greco-romana antiga. Partindo 
do estudo foucaultiano sobre o pensamento helenista, a constituição de um indivíduo como sujeito moral ativo envolve mais do que a mera tomada de consciência, pois a constituição de si mesmo depende de suas experiências - atos não só do pensamento, mas da prática, na vida. Ainda a esse respeito, Portocarrero (2009, p. 238) ressalta que

[...] nesta experiência, o elemento preponderante é a possibilidade de o próprio indivíduo: a) circunscrever a parte de si mesmo que constitui o objeto de sua prática moral, b) definir sua posição em relação ao preceito que respeita, c) estabelecer para si mesmo um modo de ser que deverá ter o valor moral de realização de si mesmo. Para tanto, ele age sobre si mesmo, procura conhecer-se, aperfeiçoa-se, transforma-se.

Entendemos que o processo desenvolvido por Rotberg, de algum modo, possui os elementos preponderantes acima citados: admitindo como verdadeiro o conhecimento científico sobre a hanseníase - que desde os anos de 1950 não mais recomendava o isolamento compulsório - e o sofrimento imputado pela prática isolacionista, o médico constitui o núcleo a partir do qual "procura conhecer-se, aperfeiçoar-se, transformar-se", tal como destacado por Portocarrero (2009) na citação acima.

Das práticas do cuidado de si que Rotberg possa ter empreendido, só tivemos acesso à sua palavra escrita - a coleção dos artigos da revista por ele fundada e a transcrição de alguns trechos de suas entrevistas ao Projeto Memória da Hanseníase, ambos citados anteriormente. Entendendo o exercício da palavra, nesse caso, escrita, como uma das formas possíveis de subjetivação de si sobre si, ou seja, um trabalho de modificação de si mesmo, lembramos que tal processo liga-se à parrhesía, ao dizer verdadeiro, porque

[...] o dizer verdadeiro é intrínseco às práticas de si, que são técnicas da Antiguidade grega voltadas para a vida considerada como uma obra de arte. Esta é uma ética que diz respeito à uma estética da existência, uma arte de viver como governo da própria vida, cuja finalidade é darlhe a forma mais bela possível [...]. O dizer verdadeiro é imanente às práticas que, na Antiguidade grega, buscam uma existência bela, brilhante, heróica, por meio do cuidado de si, da elaboração de si, do governo de si. [...] Sócrates, por exemplo, poderia ser considerado um parrhesiastes [aquele que diz a verdade] porque vivia de acordo com suas afirmações diante do risco da morte; sua coragem e austeridade no cuidado de si davam beleza à sua existência. (PORTOCARRERO, 2009, p. 230-231, grifo do autor)

O mesmo material que consideramos, contudo, poderia levar a outras suposições, como por exemplo: tendo, enfim, se livrado do domínio de Salles Gomes, estando, enfim, livre de tudo aquilo que o fez sofrer em silêncio, que o fez errar em sua prática médica, Rotberg dedica o resto da sua vida à causa de lançar, ao esquecimento, práticas e discursos que permanentemente o lembravam de barbaridades cometidas, assumindo uma atitude um tanto fanática. Se assim foi, não poderíamos pensar na coragem da verdade, disposição que necessaria- 
Sá, M. B.; Siqueira, V. H. F.

mente sustenta a série 'cuidado de si - governo de si - dizer-verdadeiro (parrhesía) - cuidado do outro - governo do outro', pois

[...] uma coragem que não seja carregada pela paixão crítica do verdadeiro é um fanatismo vão, uma energia vã; por sua vez, uma verdade que não exige, para ser proclamada, uma firmeza da alma, uma tensão ética, torna-se "inútil e incerta", para retomar as palavras de Pascal. Então, que coragem é essa que, para se manifestar supõe a instância de falar francamente? Qual é essa verdade cuja condição de possibilidade não é lógica, mas ética? (GROS, 2004, p. 11)

Ao assumir um compromisso consigo e, especialmente, porque se encontra na responsabilidade de ensinar a outros, ensinar o que entende como verdadeiro, Rotberg torna-se exemplum, pois se a parrbesía, por um lado, é "a abertura que faz com que se diga, com que se diga o que se tem a dizer, com que se diga o que se tem vontade de dizer, com que se diga o que se pensa dever dizer porque é necessário, porque é útil, porque é verdadeiro" (FOUCAULT, 2006, p. 440), por outro, ela

[...] sobretudo, e fundamentalmente, é uma palavra que, do lado de quem pronuncia, vale como comprometimento, vale como elo, constitui um certo pacto entre o sujeito da enunciação e o sujeito da conduta. O sujeito que fala [escreve] se compromete. No mesmo momento em que diz 'eu digo a verdade', compromete-se a fazer o que diz e a ser sujeito de uma conduta, uma conduta que obedece ponto por ponto à verdade formulada por ele. É neste sentido que não pode haver ensinamento da verdade sem um exemplum. (FOUCAULT, 2006, p. 492, grifo do autor)

\section{Considerações finais}

Gostaríamos de retomar um último aspecto intrínseco à parrhesía e à função educativa: a "oscilação da parrhesía", como referiu Foucault (2006), ou seja, a transferência da parrhesía - da palavra verdadeira - do mestre ao aluno que aponta para a importância da conduta do mestre - aquele que sabe toda a verdade, e por isto, diz a verdade e a coloca em ato - como conduta exemplar na constituição da subjetivação do discurso verdadeiro pelos alunos.

Existem, portanto, dois elos absolutamente fundamentais que deveriam interessar aos campos cuja formação profissional volta-se para o governo do outro, tal como a educação, a saúde e a educação em saúde: o compromisso do sujeito consigo mesmo e o compromisso do sujeito com o outro. A possibilidade da transferência de uma verdade assumida por um sujeito frente a outro, mediante todas as exigências expostas acima, no sentido de que o cuidado de si tornado governo de si - o sujeito como soberano de si mesmo - alcance o outro não apenas como governo do outro - governo das condutas do outro - mas, também, como cuidado do outro - e, dessa maneira, favoreça sua constituição como sujeito soberano de si mesmo. 
Hanseníase, preconceito e parrehesía: ...

\section{Referências}

ARAÚJO, A. M. A. Dossiê: a história dos filhos órfãos de pais vivos no Brasil - a separação de pais e filhos em razão da política de isolamento compulsório para pessoas acometidas pela hanseníase no Brasil. Rio de Janeiro: MORHAN, 2010. Disponível em: <www.morhan.org.br/views/upload/Dossie_Filhos.pdf >. Acesso em: 02 maio 2011.

AZULAY, R. D. De Moisés a Sabin: contribuição judaica à história da medicina. Rio de Janeiro: Garamond, 2001.

BOLETIM INFORMATIVO. Florianópolis: Associação Filatélica e Numismática de Santa Catarina, n. 54, ago. 2006. Disponível em: <http://www.afsc.org.br/boletins/boletim54/ boletim54.pdf>. Acesso em: 01 maio 2011.

BRASIL. Decreto no 968, de 7 de maio de 1962. Baixa normas técnicas especiais para o combate à lepra no país e dá outras providências. Diário Oficial da União, Brasília, n. 968, 09 maio 1962. Disponível em: <http://br.vlex.com/vid/baixa-tecnicas-especiais-combatelepra-pais-34143129>. Acesso em: 03 maio 2011.

Decreto $\mathrm{n}^{\circ} 76.078$, de 4 de agosto de 1975. Altera a denominação de órgãos do Ministério da Saúde e dá outras providências. Diário Oficial da União, Poder Executivo, Brasília, 05 ago. 1975. Seção 1, p. 9779. Disponível em: <http://www6.senado.gov.br/ legislacao $/$ ListaPublicacoes.action?id=205331\&tipoDocumento=DEC\&tipoTexto $=$ PUB $>$. Acesso em: 03 maio 2011.

Lei $\mathrm{n}^{\circ}$ 9.010, de 29 de março de 1995. Dispõe sobre a terminologia oficial relativa à hanseníase e dá outras providências. Diário Oficial da União, Poder Executivo, Brasília, 30 mar. 1995. Seção 1, p. 4509. Disponível em: <http://www2.camara.leg.br/legin/fed/lei/ 1995/lei-9010-29-marco-1995-348623-norma-pl.html>. Acesso em: 03 maio 2011.

- Ministério da Saúde. Controle da hanseníase: uma proposta de integração ensino-serviço. Rio de Janeiro: Nutes, 1989.

BROWNE, S. G. A lepra na Bíblia: estigma e realidade. Viçosa: Ultimato, 2003.

FOUCAULT, M. Vigiar e punir. 17. ed. Petrópolis: Vozes, 1989.

2002.

Os anormais: curso no Collège de France (1974-1975). São Paulo: Martins Fontes,

Em defesa da sociedade: curso no Collège de France (1975-1976). São Paulo:

Martins Fontes, 2005.

A hermenêutica do sujeito: curso no Collège de France (1981-1982). 2. ed. São

Paulo: Martins Fontes, 2006.

GROS, F. Foucault: a coragem da verdade. São Paulo: Parábola, 2004.

KLIEMANN, T. A. E. Homenagem ao prof. dr. Abrahão Rotberg (1912-2006).

Hansenologia Internationalis, São Paulo, v. 31, n. 2, p. 43, 2006. Disponível em:

<www.ilsl.br/revista/download.php?id=imageBank/77-198-2-PB.pdf>. Acesso em: 30 nov. 2012. 
Sá, M. B.; Siqueira, V. H. F.

MACHADO, K. Agora, de olho nos jovens. Radis: comunicação e saúde, Rio de Janeiro, n. 68, p.10-13, abr. 2008. Disponível em: <http://www.ensp.fiocruz.br/radis/sites/default/ files/radis_68.pdf>. Acesso em: 30 nov. 2012.

MACIEL, L. R. Em proveito dos sãos, perde o Lázaro a liberdade: uma história das políticas públicas de combate à lepra no Brasil (1941-1962). 2007. 380 f. Tese (Doutorado em História Social) - Departamento de História, Universidade Federal Fluminense, Niterói, 2007.

MONTEIRO, Y. N. Profilaxia e exclusão: o isolamento compulsório dos hansenianos em São Paulo. História, Ciências, Saúde - Manguinhos, Rio de Janeiro, v. 10, supl. 1, p. 95-121, 2003. Disponível em: <http://www.scielo.br/pdf/hcsm/v10s1/a05v10s1.pdf>. Acesso em: 30 nov. 2012.

OPROMOLLA, P. A.; MARTELLI, A. C. C. A terminologia relativa à hanseníase. Anais Brasileiros de Dermatologia, Rio de Janeiro, v. 80, n. 3, p. 293-294, 2005. Disponível em: <http://www.scielo.br/pdf/abd/v80n3/v80n3a11.pdf>. Acesso em: 02 maio 2011.

PÔRTO, A.; OLIVEIRA, B. T. Edifício colonial construído pelos jesuítas é Lazareto desde 1752 no Rio de Janeiro. História, Ciências, Saúde - Manguinhos, Rio de Janeiro, v. 2, n. 3, p. 171-180, 1996. Disponível em: <http://www.scielo.br/pdf/hcsm/v2n3/a09v2n3.pdf>. Acesso em: 20 abr. 2011.

PORTOCARRERO, V. As ciências da vida: de Canguilhem a Foucault. Rio de Janeiro: Fiocruz, 2009.

PRÁ ONDE é que eu vou? Produção: Ministério da Saúde. Rio de Janeiro: NUTES: UFRJ, 1988. 1 videocassete (18 min), son. color.

ROTBERG, A. O Brasil reconhece oficialmente a insuficiência da política convencional de controle da hanseníase e adota novas medidas baseadas na remoção das barreiras culturais da "lepra”. Hansenologia Internationalis, São Paulo, v. 1, n. 2, p. 101-105, 1976.

A história de dois apelos para banir o termo "lepra" e a dura lição para a América Latina. Hansenologia Internationalis, São Paulo, v. 2, n. 2, p. 107-110, 1977. 76-82, 1978a.

A non-stigmatizing Bible. Hansenologia Internationalis, São Paulo, v. 3, n. 1, p.

A demonstração, no campo, de estigma criado pelo homem. Hansenologia

Internationalis, São Paulo, v. 3, n. 1, p. 1-2, 1978b.

. A "tecnicamente impossível educação sobre lepra” - e uma advertência ao mundo endêmico. Hansenologia Internationalis, São Paulo, v. 3, n. 2, p. 109-112, 1978c.

. Crianças "leprosas", antes e depois do "Ano". Hansenologia Internationalis, São Paulo, v. 4, n. 1, p. 5, 1979a.

. Ajude a libertar seu próprio país do terror do leprostigma. Apelo aos leitores.

Hansenologia Internationalis, São Paulo, v. 4, n. 1, p. 1-2, 1979 b. 
Hanseníase, preconceito e parrehesía: ...

ROTBERG, A. O décimo aniversário dos "leprosos lunares". Hansenologia

Internationalis, São Paulo, v. 4, n. 2, p. 89-90, 1979c.

Sobre ética e purismo específico anti-hansen. Hansenologia Internationalis, São Paulo, v. 5, n. 2, p. 85-86, 1980.

Thanks to time, Newsweek, Siete Dias, o Cruzeiro, and others. Hansenologia Internationalis, São Paulo, v. 6, n. 1, p. 8-9, 1981.

. Limitamos ao Brasil a luta contra o leprostigma. Hansenologia Internationalis, São Paulo, v. 8, n. 2, p. 75-77, 1983.

Artigo recebido em 04/05/12. Aceito em 28/09/12. 